\title{
Research on the Construction of New Japanese Three-dimensional Teaching System Based on Information Technology Environment
}

\author{
Shi Yanyan \\ Department of Foreign Languages, Harbin University of Commerce, Harbin, Heilongjiang Province, China \\ huxih83@tom.com
}

Keywords: Japanese Teaching System, Information Technology, Construction Method

\begin{abstract}
Information technology uses the principles and methods of information science to acquire, transmit, process and apply information. It covers a microelectronic technology, computer technology, communication technology and sensing technology as an integrated technology and method system. The multimedia computer-based information technology has become an indispensable tool for teaching and student learning and has been naturally integrated into teaching. It completely changes the traditional teaching methods based solely on teaching materials, chalk and blackboards. Teachers, according to the teaching content or problem-solving tasks, are ready to use computers and other tools to display teaching content and discuss issues.
\end{abstract}

\section{Introduction}

Information technology has the characteristics of digitization, networking, multimedia, intelligence and virtualization. Its specific performance is scientific method, advanced technology, quick process, high efficiency and convenient operation. Japanese teaching, on the other hand, is based on the characteristics of the above information technology. With more and more modern teaching methods, Japanese teaching has changed the teacher-centered teaching model in traditional teaching. In the Japanese teaching mode with information technology, students become the main body of teaching, and teachers are only the initiators and organizers of teaching activities. In this way, not only give play to the enthusiasm of the students, initiative, but also cultivate students' creativity. As a result, student-teacher-student interaction not only makes Japanese teaching more informative and interesting, but also strengthens the feelings between teachers and students. Second, due to each person's genetic factors, their environment, the difference between the initial education and their own efforts, even in the same stage of development of different subjects have both commonalities and personality differences, resulting in some students in the classroom " Inadequate to eat, "while the other part of the students" can not eat "is not conducive to the cultivation of students personality, but also dampened the enthusiasm of some students, by contrast, using information technology is conducive to the students personality to find their own accurate positioning , But also conducive to the common creation. In addition, with the help of information technology, the teaching cost is greatly reduced, teaching efficiency is effectively improved, and students become the masters of learning. This not only enhances the students' interest in learning but also digests and absorbs the learned knowledge so as to greatly improve the learning efficiency [1].

\section{The Role of Information Technology in Japanese Teaching}

Human's thinking space is three-dimensional, that is, language (words, symbols, sounds), images (specific images, abstract images) and sound (natural sounds, artificial sounds). However, our traditional education has long been confined to almost one-dimensional Speech space, so that students learning process is abstract, rigid, static. As far as Japanese teaching is concerned, students lack internal motivation and lack of space for 3D learning. The use of multimedia illustrations, audio and video simultaneously, will be dynamic will change, the image of the visual characteristics 
of creating a variety of situations for students to create a good learning environment, can arouse the participation of the various senses of students to mobilize the students a strong desire to learn to inspire them Learning motivation and interest. For example, during the practice of Japanese conversation, teachers should create conditions for students to experience the fun of conversation, give students a choice, let them choose the content of conversation, set goals, choose methods, cultivate students' autonomy, and encourage students to complete Have some challenging tasks for themselves, so that students experience a sense of accomplishment. When arranging extracurricular assignments, teachers should enable students to collect information on educational thematic web sites, find out relevant information, broaden their study space and enrich their online resources to the existing Japanese language teaching so as to make the teaching of Japanese be three-dimensional, pluralistic, contemporary, relevant and effective Sex. At the same time, students can also choose to read materials in extracurricular, expand the reading surface, increase reading volume, purposely collect and organize the required information [2].

Large-capacity, fast-paced, diversified network document is the most important feature. Chinese and Japanese education sites generally have thematic columns, such as: a variety of Japanese test database, courseware library, Japanese materials and other columns, teachers can download the relevant Japanese video clips from the Internet, these pictures, text, sound and material processing into courseware, so that it enriched the teaching content, has been a good teaching effect. "Those who know are better than those who are well-informed, and those who are better informed are less informed." Only when students have a strong interest in what they have learned can they actively motivate their exploration. In the classroom teaching, teachers should pay attention to the students' subjectivity, properly use the information network teaching, hypertext links to achieve time span, vivid video images instantly show, in the beautiful sound of the music, in video, 3D animation illustrations Scenarios, teaching focus, the difficulties solved.

\section{Japanese Professional Teaching Quality System Reform Measures}

Teaching evaluation is the guarantee of teaching quality. According to the current situation of college evaluation system in our country and the goal of talent training in this major, the author tries to think about the reform measures of Japanese teaching evaluation system in applied undergraduate colleges from the following two aspects. The main body of Japanese teaching evaluation is the two-way change from teacher-student independence. Teachers and students are the important carriers of university teaching quality [3]. They are the two pillars in the university evaluation system. This transformation puts the ultimate goal of education at the core of evaluation, Mutual evaluation with students, students assess each other. At the same time, the employer as the ultimate beneficiary and judge of college education, the evaluation must be included in the evaluation system. Traditional Japanese teaching is characterized by the one-time evaluation of evaluation criteria and the one-time. The limitations of this method is not conducive to the overall development of students, it is difficult to develop students' innovative awareness and practical ability. Therefore, it is of great significance to introduce a variety of evaluation methods into the evaluation activities. In daily teaching, the proportion of classroom activities evaluation should be strengthened, daily teaching files should be drawn up, and the advantages and disadvantages of a test should be avoided. And the methods such as interview, questionnaire and project learning should be weighed according to students' basic knowledge, intelligent differences and learning interests Evaluation criteria, through evaluation to achieve the purpose of improving students' interest in learning.

The main body of evaluation is from a single to diversified, social change. Advocacy of social assessment and university self-evaluation, as soon as possible to establish an independent socialized scientific evaluation system. The establishment of foreign university evaluation system meets the needs of society as the basic orientation. The ultimate goal of this "demand" is that innovative personnel training can meet the needs of economic and social development. Through the timely investigation of the industry, the industry's demand for talent builds a social-oriented evaluation system. Japanese professional survey of several enterprises and institutions and employment records of several graduates show that enterprises are increasingly demanding the comprehensive ability of 
Japanese-language professionals. In terms of quality, there is a high demand for professional ethics, organization and coordination ability, language expression ability and anti-frustration ability. In terms of knowledge, emphasis should be put on solid language knowledge and professional basic knowledge. In terms of skills, in addition to computer application capability, emphasizing strong Japanese ability to speak and speak and strong intercultural language communication skills, and emphasizing the basic ability to engage in basic work related to business, foreign trade, management, tour guides and other professional fields. With the economic development, changes in the mode of production, changes in the mode of operation of enterprises, occupational posts showed a trend of compound type and integration. Therefore, there is an urgent need to establish a socially oriented evaluation system in Japanese teaching so that the teaching reform can meet the needs of social and economic development.

\section{Applied Information Technology in Japanese Teaching Strategies}

Information technology as a tool, its integration with subject teaching is the development direction of classroom teaching reform. The development trend of the modern Japanese classroom teaching mode will change from the current "teaching-based" to "teaching-supplemented" and the "humanistic" teaching mode, in which students use all kinds of information technologies to acquire knowledge and abilities [4].

The application of information technology in modern Japanese teaching can be a lot of benefits, but must be reasonable and effective application, and vice versa will be more effective. (l) It should follow the normal teaching rules. Teaching methods have changed, but also need to follow the teaching rules and the characteristics of the physical and mental development of students. Therefore, teachers still have to deal with the teacher-led and student-centered relationship in the teaching process. Teaching process always adhere to the people-oriented, student-centered, give full play to the role of teachers. Teachers in the use of information technology as an aid to give their presence to give play to leave room for students and teachers to communicate, so that modern teaching methods to better adapt to the characteristics of age and subject characteristics of students so that teachers and students Bilateral activities can be smoothly carried out to better improve teaching quality. (2) Carefully handle the relationship between traditional teaching methods and modern teaching methods. As one of the modern teaching methods, information technology has its own salient features. However, traditional teaching methods also have their own strengths and are still effective and commonly used teaching methods. Therefore, paying attention to the shortcomings of overcoming the traditional teaching methods in the teaching process and combining the advantages of the traditional teaching methods with modern teaching methods can not only improve the quality and efficiency of classroom teaching, but also improve the environment of teaching and learning for teachers and students. Help to improve the effectiveness of classroom teaching. (3) Actively guide students to make rational use of information technology. While making full and rational use of information technology in the classroom, students should be encouraged to make rational use of the information outside the classroom. There is no lack of suspicion of abuse among the learners. Individual students will use the information technology to watch TV shows, movies and even games without any restrictions. At this time, teachers should give full play to their guidance and limit their excessive behavior. For example, a teacher may leave some pictures of students in class or a Japanese conversation after the class is over so that students can use the internet to find answers. This will not only consolidate the classroom knowledge, but also effectively control the learner's extra-curricular learning time [5].

According to the actual teaching contents, teachers can adopt many teaching methods such as visual teaching method and listening and speaking teaching method, such as conducting classroom class session performances, group discussions, word soldering, students as teachers, and five-minute small essay teaching activities. What needs to be specially pointed out is that the traditional Japanese teaching mode focuses on skills training, and students can not acquire a truly high level of language ability and communicative competence. Immersion teaching methods teach nonverbal knowledge courses in Japanese as a medium, and students' Japanese proficiency can be 
improved in the process. This pedagogy can give full play to its role in basic Japanese teaching as a foreign teacher.

\section{Conclusions}

In Japanese classroom teaching with information technology, teachers can only act as planners, organizers, mentors and gatekeepers of classroom activities, and only serve as a guide, inspiration and consensus. Teachers should give students more space for thinking, not exhaustive, arranged for students to do everything. Teachers should give more time to students so that students can experience the fun of innovation and self-study in practice. The implementation of information technology in Japanese subject teaching is bound to bring about great changes to the contents of Japanese courses, curriculum implementation, curriculum resources, teaching evaluation and students' learning styles, and to promote the improvement of Japanese teaching effectiveness.

\section{References}

[1] Li Gang. Thoughts and Attempts on Effective Integration of Information Technology and Japanese Teaching [J]. Examination Weekly. 2008 (42):19 23.

[2] Zhao Jiannong. The application of information technology in Japanese teaching practice [J]. Modern Vocational Education. 2016 (09) :76 82.

[3] Wang Wei. Pros and cons of multimedia Japanese teaching analysis and related countermeasures [J]. Modern Vocational Education. 2014 (02) :108 112.

[4] Lu Wenjing. Problems and Countermeasures of Japanese Teaching in Higher Vocational Colleges under the New Situation [J]. Helijiang Science. 2017 (22) :95 103.

[5] Zheng Jie. Based on the online learning model analysis of Japanese teaching innovative ideas [J]. Theater House. 2017 (24) :77 79. 